\title{
Women's Small-Medium and Micro Enterprises as Engines for Income-Poverty Alleviation: A Renewed Approach to Tackling Urban Poverty in South Africa
}

\section{Loretta Muzondi}

\author{
Department of Development Planning and Management \\ University of Limpopo, Turfloop Campus, South Africa \\ loretta.muzondi@ul.ac.za
}

Doi:10.5901/mjss.2014.v5n23p632

\begin{abstract}
Poverty deprives people of their rights to socio-economic well-being. Forthwith, lack of income inherently worsens the plight of the poor and further deteriorates their living standards. The resultant of income-poverty is failure to afford basic needs such as food, health and education, amongst others. Basically, women and children are the most vulnerable when it comes to the manifestation of poverty and its social ills. Income-poverty is unquestionably the greatest challenge facing developing countries. As a result of high unemployment rates in most developing countries, urban poverty remains a threat to development. However, there appears to be some hope in the continued fight against poverty as Small-Medium and Micro Enterprises (SMMEs) are taking a stand as a strategic approach to income-poverty alleviation in developing countries. On that note, in South Africa, Women's Small-Medium and Micro Enterprises (WSMMEs) are gaining momentum as a strategy to income-poverty alleviation. The paper strongly believes that women engaged in SMMEs have the potential and capacity to contribute to economic development, job creation and ultimately income-poverty alleviation. Theoretically, this paper reveals the positive relationship between WSMMEs and income-poverty alleviation. Additionally, the paper argues that WSMMEs contribute to a greater extent on the improvement of households' living standards. Therefore, the paper concludes that although WSMMEs face a wide array of challenges, ranging from lack of finance, lack of equipment, poor access to business training and lack of information on institutional support, amidst others, their contribution towards income-poverty alleviation can be reckoned as indispensable.
\end{abstract}

Keywords: Income-poverty, Urban poverty, Women's Small-Medium and Micro Enterprises

\section{Introduction}

Globally, lack of income has inevitably driven quite a capacious number of poor people to engage in different income generating initiatives in the form of livelihoods and amongst these are the Small-Medium and Micro Enterprises (SMMEs) (Sadeq, 2008). The positive relationship between SMMEs and income-poverty alleviation is not a new phenomenon, it dates back to 1725, when Cantillon established the positive link between the two concepts (Agyapong, 2010). It has been observed that poor households have the capacity to escape from income-poverty by engaging themselves in small business ventures (Viljoen, 2008). Consequently, in the pursuit of reducing the magnitude of their vulnerability to incomepoverty, women are compelled to increase their income earnings by embarking on SMMEs, hence the emergence and existence of Women's Small-Medium and Micro Enterprises (WSMMEs). WSMMEs are common in South Africa (SA) and they are acknowledged as the driving force towards local economic development, job creation and ultimately incomepoverty alleviation (Tambanun, 2009). South Africa is considered to be one of the developing countries, particularly in the African continent. However, income-poverty in urban SA is still a hefty challenge so much such that households resort to partaking small business ventures in a bid to earn a living. However, WSMMEs are failing to grow and expand due to the challenges which they are facing in the market such as lack of institutional and financial support. The challenges are alluded to the legacies of the apartheid era and also the gender inequality that is experienced within the male-dominated industry of the SMME sector (Viljoen, 2008).

Drawing from this discourse, it is globally accepted that women are basically care-givers of families and their role in the upkeep of the family is essential. Subsequently, women are faced with a mammoth of challenges that are often liable for the poor well-being of themselves and their children (Kirby and Watson, 2008). In cases where the households are female-headed, the severity of poverty is most experienced to such an extent that they fail to; acquire descent accommodation, maintain a balanced diet and send their children to school. However, not only women who head houses suffer from poverty, as insinuated by the United Nations (UN) (2012) that the most poverty-stricken people are generally 
women and children. To gain a better understanding of the nature of WSMMEs, it is crucial to define them. Important to note is that the definition of SMMEs varies across countries. However, Tambanun (2009) defines a micro enterprise as an enterprise which employs less than five full time equivalent employees. A small enterprise can range from 5-20 employees and a medium ranges from 20-50 employees. He further defines WSMMEs as SMMEs that are owned and headed by a female/woman. In order to understand the dearth of income-poverty and its social ills, the term is further discussed in the following section.

\section{The Dynamics of Income-Poverty and Urban Poverty}

According to the United Nations Development Program (UNDP) (1998 cited in Sadeq, 2008), income-poverty is defined as "the lack of minimally adequate income or expenditures". The UNDP (2002) further expands on its definition by explaining that income-poverty describes a person or family who lives on or below the minimum acceptable way of life. Henceforth, income poverty is most likely to occur in people who have a low income such as women, children, lone parents and the disabled. Generally, poverty is complex and dynamic in nature, therefore, it is important to understand that lack of income is the core-cause of poverty in the context of this paper. Viljoen (2008) relates income-poverty to the international poverty line that was set by the World Bank (2002) which was developed mainly for the purposes of crosscountry comparisons. The international poverty-line was set at one United States dollar per day. Therefore each household that survives below the stipulated poverty line is a poor household. Siringi (2011) holds that lack of employment and cash earnings was proven to be a particular characteristic of income-poverty, resulting in the inability to acquire basic food, clothing and shelter which culminates in triggering the lack of personal security. Taking that into cognizance, one can argue that women find themselves trapped in a burdensome scenario, with the exposure to all the stresses of day to day survival and family insecurity. With this in mind, Sadeq (2008) advocates that the assessment of the cause-effect relationship with variables such as education, health and infrastructure, which have major attribution to poverty, is vital. He finds that low-income is an obstacle to gaining access to income-earning capabilities, nutritious food and education. From this ideology, it can therefore be argued that if women's access to education, training and physical infrastructure is increased, then their capabilities are widened and they can take a better stand in alleviating incomepoverty.

As noted by Sadeq (2008), women basically suffer from income-poverty because of poor paying jobs, expanding labor-force and the unique problems associated with female-headed households. Harrison (2008) re-iterates that the incidence and severity of income-poverty is greatest amongst female-headed households and this is according to his findings after conducting a study using the analysis as a unit of measure. Tambanun (2009) observes and confirms that the key indicators of income-poverty especially amongst women are voicelessness, powerlessness, lack of knowledge, poor purchasing power, social exclusion and alienation from access to economic opportunities. Therefore, the manifestation of the above mentioned indicators envisages the synopsis of urban poverty in most developing countries.

Urban poverty is usually under-estimated owing to survey methods and inherently influenced by the general consensus that the poor are found commonly in rural areas (Viljoen, 2008). Siringi (2011) establishes that the dynamism of income-poverty depends largely on the circumstances and assets that people can access and acquire to protect themselves against shocks. His opinion is that poverty trends fluctuate with time especially in urban areas as people move in and out of poverty over time relative to the availability of economic opportunities. Sadeq (2008) utilized the headcount methods to analyze and assess the poverty incidence in urban poor households. However, Agyapong (2010) questions if the head count methods can successfully account for the skills and assets of the urban poor households. He challenges that view by arguing that the headcount methods are ineffective and are bound to provide inaccurate data as skills and assets of urban poor households are typically under-counted and subsequently under-estimated in poverty assessments and poverty reduction programs. Considering the nature of income-poverty and also urban poverty, one can therefore comprehend that income-poverty alleviation can be significantly achieved if external support focuses on what matters most to the people in a way that is congruent with their livelihood strategies, social environment and ability to adopt.

\section{Challenges Faced by WSMMES}

In opposition of the general consensus that women cannot operate their own businesses ventures, overwhelming evidence has shown that, just like males, females also have great potential and are capable of effectively running their own SMMEs (Berry, Van Blottnitz, Cassim, Kesper, Rajaratnam and Van Seventer, 2009). However, their capacity is hindered by the myriad of challenges that they face externally in the SMME industrial sector market and internally within 
their SMMEs (Wennekers and Thurik, 2007; Berry et al, 2009). In their efforts to alleviate income- poverty, women are confronted with a variety of challenges in developing and running a business, and many researchers argue that significant barriers still exist for women who are establishing and growing their businesses (Wennekers and Thurik, 2007; Berry et al, 2009: Witboi and Ukpere, 2011). A logical assumption that could explain the failure of most small business initiatives by women might be that of lacking information on how to further develop their businesses. On that note, Siringi (2011) believes that the success of both starting and sustaining a business usually results from prior experience. In view of this, it could be possible that women's previous work experience or entrepreneurial training of some sort impacts on the start-ups and survival of women-owned SMMEs. Most challenges that have been observed to hinder the growth of WSMMEs include access to information, access to skills and training, and, access to finance (Bessant and Tidd, 2007; Mutezo, 2009). All the afore-mentioned challenges are further discussed below.

\subsection{Access to information}

Without access to information, women tend not to be knowledgeable about financial institutions and government bodies that can assist them with funds to start up and sustain their businesses (Bjerke, 2007). In addition, women might not even be aware of fellow women with whom they can form partnerships in order to strengthen their businesses. Bessant and Tidd (2007) are of the opinion that small enterprises in South Africa are unaware of government initiatives to support them or, if they happen to be aware, they have not yet used them. This is not a surprise because they might not know the procedures that they have to follow in order to access such support programs. It is therefore necessary for information hubs and campaigns to be introduced in order to ensure that women have access to information.

\subsection{Access to management skills and training}

According to Mutezo (2009: 225), "exposure to management experience impacts on the management skills of entrepreneurs". Managerial competencies are sets of knowledge, skills, behaviors and attitudes that contribute to personal effectiveness (Underwood, 2012). Tambunun (2009) concedes that managerial competencies are very important to the survival and growth of new SMMEs. Harrison (2008) found that lack of managerial experience and skills are the main reasons why new firms fail. In South Africa, for example, Witboi and Ukpere (2011) point out that lack of education and training has reduced the management capacity in new firms. This is therefore one of the reasons for the low level of entrepreneurial creation and the high failure rate of new ventures.

One can therefore argue that women will only know about relevant government bodies when they are well informed with regard to where and how to access them. Consequently, if women have access to government bodies, they can easily contact them and seek assistance with their businesses. However, Mutezo (2009) asserts that it might still be difficult for women to sustain their businesses if they do not have business and communication skills. Harrison's stance (2008) is that women lack education training and management know-how on the running of their SMMEs that is the reason why they eventually fail in the long run. Sedeq (2008) is of the same opinion and maintains that education is the most influencing factor for developing human skills, knowledge, attitudes and values. His study indicates that $66 \%$ of the sample respondents identified education and training as the major constraints to the success of WSMMEs and the possession of appropriate knowledge will, therefore, enable women to be successful in their businesses. However, Witboi and Ukpere (2011) disputes that fact by pointing out that women are well knowledgeable on how to run their SMMEs but the challenges they are facing arise from the external environment. Whereby the SMME sector is characterized by massive gender inequality since the SMME industry is dominated by men, women are thus disadvantaged relative to men. Witboi and Ukpere (2011) further recommend for a change in societal attitudes and the transformation of traditional institutions in support of women in their endeavor to alleviate poverty through SMMEs.

\subsection{Access to finance}

All businesses require financial resources in order to start trading and to fund growth, of-which, lack of access to finance can be a constraint on business growth (Berry, et al, 2009).Viljoen (2008) advises that whether business owners can access adequate and appropriate finance to grow or not, is a particular concern for policymakers, who are expected to formulate and implement policies that enhance a conducive environment for the growth of SMMEs. Siringi (2011) ascertains that new SMMEs can be financed from founders' own wealth and/or by accessing external sources of finance, whether from 'informal' sources such as family and friends, or from 'formal', market-based sources such as banks, venture capitalists and private equity firms. Furthermore, once businesses are trading, further development can be 
financed using retained profits. According to Lopriore (2009), access to finance is a major problem for the South African entrepreneur. Concurrently, lack of financial support is the second most reported contributor to low new firm creation and failure, after education and training in South Africa (Tambanun, 2009).

One can therefore deduce that in order for any business to succeed, there is a need for capital investment. Consequently, the lack of access to information will negatively affect the rate at which women can acquire funds. Previous studies show that a significant factor for the perceived failure of WSMMEs is the degree of the financial support (Sadeq, 2008; Agyapong, 2010; Siringi, 2011; Underwood, 2012). The women in the samples of the afore-mentioned studies appeared to have a concern over obtaining financing from financial institutions and government agencies. It is the lack there-of that hinders the success of WSMMEs and becomes a barrier to growth and development. These results were also further reflected in the study by Harrison (2008). The study was successfully conducted as 140 women formed part of the respondents and they named lack of financial support as a huge challenge hindering the success of WSMMEs. In as much as women face challenges in acquiring financial support for their SMMEs, women however have a tendency of spending all the income generated from the SMMEs solely on the households' welfare, which limits them when it comes to investing in economic activities (Berry et al, 2009). Therefore, investments of profits also need to be prioritized when giving advice to women in business.

\subsection{Location and networking}

Location has impacts on the market potential and growth opportunities of new firms (Tambanun, 2009). Geographical proximity to either critical buyers or suppliers produces a form of enhanced environmental scanning that enables new firms to more easily identify and exploit growth opportunities in the market and it impacts on the market prospect of new firms (Agyapong, 2010). Networking is very important to SMMEs, both new and established and can positively impact on their performance and access to finance. Siringi (2011) found that the formation of networks helps entrepreneurs to tap resources in the external environment successfully. In addition, networks increase a firm's legitimacy, which in turn positively influences the firm's access to external financing. Harrison (2008) infers that in the absence of effective market institutions, networks play an important role in spreading knowledge about a firm's existence and its practices. Networks also help a firm learn appropriate behavior and therefore obtain needed support from key stakeholders and the general public. One can therefore derive that networking can positively impact on the growth of new SMMEs and without proper networking, WSMMEs are bound to fail in the long-run.

\subsection{Investment in information technology and cost of production}

Investment in technology and keeping up with Information Technology (IT) is increasingly important to all firms (Siringi, 2011). Pretorius (2007) accepts that technology plays a crucial role in the development of new SMMEs and it also acts as a catalyst in maximizing business opportunities. Hence, IT is perceived as essential to achieve desired sales. Since the use of technology involves costs to be incurred through acquiring computer hardware and software, new SMMEs without access to capital may find it difficult to purchase necessary technology and ultimately, the cost of production can affect the growth of new SMMEs. To note also is the fact that women shun away from technological innovations and prefer to keep their businesses informal and traditional, all because of lack of skills and knowledge (Siringi, 2011). Another issue is that of the rising costs of inputs in South Africa especially the cost of electricity and petroleum which can constrain growth. Therefore a close monitoring of costs of production is necessary in order to reduce wastage and determine the most efficient means of production (Sadeq, 2008).

\section{Women's Motivation for Venturing into Business}

It is believed that different motivations for starting a business lead to different business outcomes, which in turn affect growth levels amongst enterprises (Viljoen, 2008). Therefore, the higher the ambitions of an entrepreneur, the higher the chances are for that business to grow and engage in various sectors. Cocks (2008) identified push and pull factors as the key drivers of motivation behind WSMMEs. The 'push' factors are a no-choice case, whereby an individual is forced by circumstances to venture into business (Harrison, 2008). In the opinion of Kirby and Watson (2008), women are normally pushed into entrepreneurship when they are unhappy at work, dissatisfied with the salary they are earning, unemployed and, in most cases because of no other available alternative to earn a living.

There are basically 7 kinds of motivation that drive women to embarking on WSMMEs and these are: Dynastic compliance; whereby a woman replaces a spouse in a family business until such time that the rightful successor takes 
over; Had no other choice, these are those who lack educational and professional experience. They opt for entrepreneurship in order to earn a living; Entrepreneur by chance, these are women who are pushed into business due to personal or family circumstances, but they do have a supportive environment; Natural successor, these are women who inherit the business from the family, and are well prepared to take over the business; Forced entrepreneurs; they are women who decide to go into business because of the 'push' factors; Informed entrepreneurs, these are professional women who have always had knowledge about entrepreneurship interests and also high family demands, but still decide to become entrepreneurs; lastly, Pure entrepreneurs are women with innovative ideas that they want to transform into reality. Henceforth, women's decisions on entrepreneurship are influenced by a variety of factors.

\section{The Significance of WSMMES in Income-Poverty Alleviation}

WSMMEs are common in South Africa (SA) and they are regarded as the driving force towards local economic development, job creation and ultimately income-poverty alleviation (Tambanun, 2009). South Africa is considered as one of the developing countries, particularly in the African continent. However, income-poverty is still a hefty challenge so much such that households resort to partaking in small business ventures in a bid to earn a living. In an effort to address the problem of poverty, the government of SA has been assisting the SMME sector through its developmental initiatives such as the Local Economic Development (LED).

The value of WSMMEs is recognized in all economies world-wide, irrespective of the economy's developmental stage (Wennekers and Thurik, 2007). Kirby and Watson (2008) state that a major reason why WSMMEs have been receiving increased attention from both scholars and the public press is the growing recognition of the substantial economic and social contributions entrepreneurship brings. Bjerke (2007) agrees and offers that the economic contributions include economic growth, maintaining a favorable balance of payments and balance of trade, and, employment creation. Bessant and Tidd (2007) provides evidence that the contribution towards economic growth, job creation and social progress is valued highly and WSMMEs are regarded as an essential element in a successful formula for achieving economic growth. According to Lopriore (2009), SMMEs in the United Kingdom employ $62 \%$ of the labor force and contribute 25\% to GDP. In the European Community as a whole, the SMME sector employs $66 \%$ of the work force. Mutezo (2009) emphasizes the major role SMMEs play in the European Community, by citing the employment generated by SMMEs in various European countries. He suggests that SMMEs contribute $79 \%, 63 \%$ and $60 \%$ to employment creation in Italy, France and Germany respectively. Underwood (2012) endorses that over 99\% of the 3.2 million businesses in the UK are SMMEs and they account for more than two thirds of the business turnover.

A study conducted by Berry et al (2009) in Southern Africa region indicates that about $20 \%$ of the labor force is employed in micro and small enterprises in the six countries of the Southern African region, which include Botswana, Kenya, Lesotho, Malawi, South Africa, Swaziland and Zimbabwe. The number of people engaged in micro and small enterprises' activities per 1,000 persons in the population was found to range from 70 to 90 persons in Botswana, Kenya, Lesotho, Malawi and South Africa. In Zimbabwe and Swaziland it ranged up to 110 or more. Furthermore, estimated employment in these micro and small enterprises was found to be twice the level of employment in registered large-scale enterprises and the public sector. Therefore, SMMEs are no doubt a major source of livelihood for a big portion of the population in the region. Income and employment are central issues when considering the role of SMMEs in any economy as both items are the most important socio-economic contribution SMMEs make for the country (Mutezo, 2009). For instance, Bessant and Tidd (2007) discuss the contribution of SMMEs in Southern Africa as follows "the contribution of SMMEs is seen in generating employment and income of-which it has become increasingly recognized not only in Southern Africa but also around the world. In most developing countries these contributions appear to have been increasing over time (Agyapong, 2010). It is therefore estimated that SMMEs employ 22\% of the adult population in developing countries. Bessant and Tidd (2007) estimate that SMMEs represent over $90 \%$ of private business and contribute to more than $50 \%$ of employment and of GDP in most African countries.

The issue of women entrepreneurship is gaining popularity across the globe. The participation of women is increasingly being viewed as one of the prime contributors in economic growth (Siringi, 2011). Irrespective of woman's involvement in small-medium-scale enterprises or in the informal/formal sectors, their contribution to output and value addition is substantial (Underwood, 2012). Women entrepreneurship is not only necessary for their economic survival but also for strengthening the social system (Bessant and Tidd, 2007).

Fostering women's entrepreneurship development is therefore crucial for economic growth and development and the participation of women entrepreneurs in small business enterprises is very encouraging in some African countries (Dignart and Havet, 2009). For example, in Ghana women-owned small-scale enterprises have a great capacity to alleviate unemployment and to contribute to the economic growth of the country. WSMMEs have been identified as 
contributing much in a society including enhancing job creation through innovations and creativity as well as aiding human resources development (Siringi, 2011 and Underwood, 2012). Agyapong (2010) acknowledges that WSMMEs stimulate investment interest in new ventures formed and they are flexible enough to respond quickly to customer and market demands. They open up new economies and set-up new markets which is a definitive measure towards economic growth and development. Underwood (2012) confirms that WSMMEs do contribute much to reducing income poverty. Therefore women involved in SMMEs have the capacity to deal with any shocks that are associated with income-poverty because they can generate income.

WSMMEs are an engine of both economic growth and development (Siringi, 2011). Witboi and Ukpere (2011) are of the same idea and point out that WSMMEs provide income and employment generation for significant proportions of women. Sadeq (2008) expands on that by supporting that the WSMME development is seen as an essential ingredient in the promotion of broad-based growth, improving the well-being of the poor and women by providing significant income and employment generating opportunities. Furthermore, WSMMEs also encourage women empowerment and facilitate women indigenous investment. Siringi (2011) believes that WSMMEs are also sources of government tax revenue and they contribute to a country's Gross Domestic Product which leads to economic growth. Pretorius's (2007) interpretation of the contribution of WSMMEs socially is that women, through increased participation in income generating activities, can contribute to stability and a reduction in social problems. Mutezo (2009) continues by justifying that socially, entrepreneurship results in poverty eradication and improved standards of living. WSMMEs are thus an essential panacea for improving the standards of living, more specifically for households in a society and the whole country.

In the light of the above, WSMMEs therefore play an important role to address the problems of unemployment, job creation, innovation and long-term economic development as witnessed by studies done world-wide. The overall role of WSMMEs is to provide jobs for the unemployed and entrepreneurial opportunities for individual women who want to venture into businesses (DTI, 2007). WSMMEs are also essential for stimulating competition and penetrating niche markets that are not explored by large enterprises (Cocks, 2008). The abundance of economic opportunities that exist in this sector is said to be playing a major role in attracting women entrepreneurs to participate in SMMEs.

\section{South Africa's Legal Framework on SMMES}

In an effort to address the problem of poverty, the government of SA has been assisting the SMME-sector through its national socio-economic developmental policies such as the Reconstruction and Development Program (RDP), Growth, Employment and Redistribution (GEAR), Accelerated Shared Growth Initiative for South Africa (ASGISA), the New Development Path and the most recent National Development Plan. At provincial and local levels, the Integrated Development Plan (IDP) and Local Economic Development (LED) seek to address and support small development initiatives (DTI, 2008). Having acknowledged the significant contribution of the small business-sector to income-poverty alleviation, the government of SA has been supportive of this conspicuous plausible renewed strategy towards tackling urban poverty through income generation and job creation (SEDA, 2009). The White Paper on National Strategy for Development and Promotion of Small Business of 1995, states that the SMME sector plays a key role in South Africa's socio-economic transformation (DTI, 1995). There are quite a number of SMME support agencies that were formulated to foster the development and growth of SMMEs through the Integrated Small Business Development Strategy by aiding with financial and institutional support and these include; Small Enterprises Development Agency (SEDA), Ntsika Enterprise Promotion Agency, South African Micro-Finance Apex Fund (SAMAF), Khula Enterprise Finance Limited, National Youth Development Agency (NYDA) and National Empowerment Fund (Ladzani and Van Vooren, 2008). Surprisingly, in the midst of such policies and support agencies WSMMEs still fail to grow and this may be attributed to the lack of proper information dissemination about their existence as highlighted earlier, compounded with other internal and external challenges.

\section{Conclusion}

In as much as WSMMEs face challenges globally, their capacity is overwhelming if only they are given sufficient support. Women, in particular embark on SMMEs due to the identified push and pull-factors, more-so, motivational factors also contribute to influencing the decision of women in doing business. Women ought to shift from their myth of doing business informally and professionalize all their operations so as to improve the management of their SMMEs. Firstly, the role played in employment creation and income generation is significant. Secondly, the paper has established that there is a way of reducing income-poverty in households, that is, through WSMMEs. Therefore, the promotion and development of WSMMEs through better legislation, provision of services and strengthening of all various types of 
support institutions could yield even better results. The paper has also revealed one major shortcoming which leads to a conclusion that most SMME support programs in South Africa are either inadequate or poorly implemented. This conclusion is drawn from the findings of literature survey which show that most women are not aware of the types of services which supporting structures can offer them and neither do they know how and where to acquire the support. Possible recommendations on improving the performance of WSMMEs include; Gender-mainstreaming in the SMMEsector; more emphasis on WSMMEs skills and development training to improve their business management knowledge and also marketing and advertising strategies; improved financial and institutional support from SMME agencies by addressing the WSMMEs' financial challenges and the problem of lack of equipment and technology. Therefore, as a pivotal paradigm shift towards women empowerment, WSMMEs can be deemed as a renewed approach to alleviating income-poverty in urban areas of South Africa.

\section{References}

Agyapong, D. (2010). Micro-small and medium enterprises' activities, income level and poverty reduction in Ghana. International Journal of Business Management, 5 (12): 196-205.

Berry, A., Van Blottnitz, M., Cassim, R., Kesper, A., Rajaratnam, B. and Van Seventer, D.E. (2009). The Economics of SMMEs in South Africa. Princeton, Pretoria.

Bessant, J. and Tidd, J. (2007). Innovation and Entrepreneurship. Wiley and Sons Publishers. Chichester.

Bjerke, B. (2007). Understanding Entrepreneurship. Edward Elgar. Massachusetts.

Cocks, L., Pretorius, M. (2008). Entrepreneurial education for business start-ups - an exploratory case analysis. In Proceedings: Entrepreneurship in Africa. The Road to Freedom, 6(3): 175-184.

Dignard, L. and Havet, J. (2009). Women in Micro-and Small Scale Enterprise Development. West-view Press. Colorado.

Department of Trade and Industry (DTI). (2008). Annual Review of Small Business in South Africa 2005-2007. Government Printers. Pretoria.

Department of Trade and Industry (DTI). (2007). Integrated Strategy on the Promotion of Entrepreneurship and Small Enterprises. Government printers. Pretoria

Department of Trade and Industry (DTI). (1995). White Paper on National Strategy for the Development and Promotion of Small Business in South Africa. Government Printers. Pretoria.

Harrison, P. (2008). Training needs for women-owned SMMEs. Education and Training, 50 (8): 687-697.

Kirby, D.A. and Watson, A. (2008). Small Firms and Economic Development in Developed and Transitional Economies: A Reader. Wilson Publishers. California.

Ladzani, W.M. and Van Vuuren, J.J. (2008). Entrepreneurship training for emerging SMEs in South Africa. Journal of Small Business Management, 40 (2), 315-333.

Lopriore, M. (2009). Supporting Enterprise Development and SME in Europe. Eipascope, 2 (8), 218-225.

Department of Trade and Industry (DTI). (1995). National Small Business Act. Government Printers. Pretoria.

Mutezo, A.T. (2009). Obstacles in the access to SMME finance: an empirical perspective. Journal of Small Business Management, 40 (1), 220-245.

Pretorius, M. (2007). A training model to enhance micro and small business start-ups in South Africa. D-Tech thesis. Pretoria Technikon, Pretoria.

Sadeq, A. M. (2008). Perpetual charity and poverty alleviation. International Journal of Socio-Economic Development, 29 (1): $336-350$.

Small Enterprises Development Agency (SEDA). (2009). Small Business Monitor. SEDA, Pretoria.

Siringi, E. M. (2011). Women's small and medium enterprises for poverty alleviation in Sub-Saharan Africa. Management Research Review, 34 (2): 186-206.

Tambanun, T. (2009). Women entrepreneurship in Asian developing countries; their development and constraints. Journal of Development in Agricultural Economics, 5(14): 646-657.

Underwood, P. (2012). Supporting the information needs of entrepreneurs in South Africa. Library Review, 58 (8): 96-108.

United Nations (UN). (2012). Report on Women and Development in Africa. Global Development. New York.

Viljoen, L. (2008). Support for female entrepreneurs in South Africa: improvement or decline. Journal of Family Ecology and Consumer Sciences, 29 (1): 37- 44

Witboi, M. and Ukpere, M 2011. Indigenous female entrepreneurship: analytical study on access to finance for women entrepreneurs in South Africa. African Journal of Business Management, 5 (14): 646-657.

World Bank. (2002). Enhancing the Effectiveness of Government in Promoting SMMEs, South Africa. World Bank, http://www.worldbank. org/smmepromotion/southafrica.pdf. (Accessed 11/07/14).

Wennekers, A.R.M. and Thurik, A.R. (2007). Linking Entrepreneurship and Economic Growth. Small Business Economics, 13 (1), $27-55$. 